Original Article

\title{
Changes in neck and upper trunk muscle activities according to the angle of movement of the neck in subjects with forward head posture
}

\author{
SongHee Cheon, PT, PhD ${ }^{1)}$, SoHyun Park, PT, PhD ${ }^{1)^{*}}$ \\ 1) Department of Physical Therapy, Youngsan University: 288 Joonam-ro, Yangsan, Gyeongsangnam-do, \\ Republic of Korea
}

\begin{abstract}
Purpose] This study investigated changes in neck and upper trunk muscle activities according to the angle of movement of the neck in subjects with Forward Head Posture. [Subjects and Methods] Twenty subjects with forward head postures were recruited. The activities of the sternocleidomastoid muscle, splenius capitis and splenius cervicis muscles, upper trapezius muscle, and middle trapezius muscle during flexion and extension were assessed. [Results] The activity of the sternocleidomastoid muscle showed significant differences between the $30^{\circ}$ flexed position and the full range of motion position, and between the neutral position and the full ROM position. The activity of the middle trapezius muscle showed a significant reduction in the $30^{\circ}$ extended position and the full ROM position as compared to the neutral position. [Conclusion] In the full flexed position, sternocleidomastoid muscle activity increased significantly, and during extension position, the middle trapezius muscle reduced its activities.

Key words: Forward head posture, Neck muscle activity, Upper trunk muscle activity
\end{abstract}

(This article was submitted Sep. 9, 2016, and was accepted Oct. 19, 2016)

\section{INTRODUCTION}

The sedentary life style easily leads to a forward head posture (FHP), and the clinical expenses related to FHP has increased $^{1)}$. FHP is a poor habitual neck posture that induces biomechanical changes in the head and spinal columns ${ }^{2,3)}$. FHP is strongly associated with various symptoms such as neck muscle pain and fatigue, headaches, and less motilities of the neck $^{1,2,4-6)}$.

Many researchers have studied FHP and its relationships with the neck muscles because of its prevalence in musculoskeletal disorders of the head and neck ${ }^{1,2,47)}$. However, to our knowledge, no research has reported on the neck and scapular stabilizer muscle activations according to various neck flexion and extension angles in subjects with FHPs. The previous study $^{8)}$ have only been studied in healthy individuals or have focused on either the neck muscles or scapular stabilizer muscles in a specific neck position ${ }^{7,9-11)}$.

Therefore, in this study, we investigated upper trunk and neck muscle activities according to the angle of neck flexion and extension in subjects with FHPs.

\section{SUBJECTS AND METHODS}

Twenty college students with FHPs were the subjects of this study. Lateral views of each subject were photographed to measure the craniovertebral angle, which was defined as the angle between the horizontal line running through the $\mathrm{C} 7$ spinous process and the line connecting the tragus of the external auditory meatus and the $\mathrm{C} 7$ spinous process. Subjects with

*Corresponding author. SoHyun Park (E-mail: ptpsh@ysu.ac.kr)

(C2017 The Society of Physical Therapy Science. Published by IPEC Inc.

This is an open-access article distributed under the terms of the Creative Commons Attribution Non-Commercial No Derivatives (by-nc-nd) License $<$ http://creativecommons.org/licenses/by-nc-nd/4.0/>. 
angles less than $53^{\circ}$ were considered to have FHPs ${ }^{10)}$. In this study, a TELEMYO 2400 (Noraxon, USA) was used to measure the activities of the muscles surrounding the neck. The muscle activity was measured three times in each of three positions (the neutral position, an angle of $30^{\circ}$, and a full ROM) in both neck flexion and extension in accordance with the protocols of the previous study ${ }^{8}$. The electrodes were attached over the sternocleidomastoid muscle, splenius capitis and splenius cervicis muscles, upper trapezius muscle, and middle trapezius muscle ${ }^{8,10)}$. The purpose and procedures of this study were explained to all subjects, and they provided written informed consent prior to participation. This study adhered to the Declaration of Helsinki.

The results were expressed as mean \pm standard deviation. SPSS ver. 20.0 was used to analyze the data. A repeated measure ANOVA and a post hoc LSD test were conducted to determine muscle activity according to neck movement angles. Statistical significance was accepted at values of $\mathrm{p}<0.05$.

\section{RESULTS}

In the present study, we observed changes in neck muscle activity according to neck position. There were significant differences in the muscle activities of the sternocleidomastoid muscle and middle trapezius muscle $(\mathrm{p}<0.05)($ Table 1$)$. The activity of the sternocleidomastoid muscles showed significant differences between the $30^{\circ}$ flexed position and the full ROM position, and between the neutral position and the full ROM position $(\mathrm{p}<0.05)$. For the activity of the middle trapezius muscle, it showed a significant reduction in the $30^{\circ}$ extended position and the full ROM position compared to the neutral position $(\mathrm{p}<0.05)$.

\section{DISCUSSION}

This study investigated upper trunk and neck muscle activities according to the angle of neck flexion and extension. We compared three neck flexion positions: (1) neutral neck position, (2) $30^{\circ}$ degree neck flexion (3), and maximum neck flexion. We also compared three neck extension positions: (1) neutral neck position (2) $30^{\circ}$ neck extension, and (3) maximum neck extension. The results showed that the sternocleidomastoid muscle and middle trapezius muscle activities are different according to neck position.

The first finding of this study was that the activation of the sternocleidomastoid muscle was greatest in the full flexed position, but there were no significant differences between the neutral and middle ranged neck flexion. Lee et al. ${ }^{8)}$ reported that sternocleidomastoid muscle activities between the neutral and middle range neck flexion also have significant differences in healthy adults. They suggested that the mean data of activations of the sternocleidomastoid muscle in the neutral position demonstrated $3.34 \pm 2.2$, which was lower than we found in our study. Therefore, we assumed that higher activations of the sternocleidomastoid muscle in the neutral position in subjects with FHP would not be able to cause significant differences between the neutral and middle range neck flexed position. We also presumed that the muscle activities of the sternocleidomastoid muscle were significantly activated in the full flexed position in subjects with FHPs. Cheng et al. ${ }^{7)}$ reported that sternocleidomastoid muscle activities are significantly increased with the increasing flexion and extension angles, which is similar to the trends found in our study.

Moreover, we found that greater neck extension angles showed less muscle activation in the middle trapezius. A previous study ${ }^{9}$ reported that the activation of the middle trapezius increased significantly in the slouched sitting posture compared to the erect one. Furthermore, Gaffney et al. ${ }^{11)}$ reported that scapular adduction was coupled with cervical extension. Therefore, we estimate that the middle trapezius is reduced in cervical extension because it may lead to scapular adduction.

The limitations of this study were that we did not measure the neck and scapular motion. Thus, we were not able to determine the relationships between scapular movements and neck motions, which could affect the upper trunk and neck

Table 1. Comparison of muscle activities according to the neck position

\begin{tabular}{llccc}
\hline Muscle & Action & Neutral & 30-degree angle & Full ROM \\
\hline Sternocleidomastoid muscle & Flexion & \multirow{2}{*}{$4.71 \pm 4.09$} & $5.36 \pm 4.58$ & $7.28 \pm 6.15^{\mathrm{b}}$ \\
(\%MVIC) & Extension & & $6.72 \pm 4.77^{\mathrm{a}}$ & $9.45 \pm 8.82$ \\
Splenius capitis \& Splenius cervicis & Flexion & \multirow{2}{*}{$13.37 \pm 16.63$} & $14.98 \pm 18.67$ & $14.65 \pm 13.25$ \\
$(\%$ MVIC) & Extension & & $12.16 \pm 14.57$ & $13.14 \pm 13.26$ \\
Upper trapezius & Flexion & \multirow{2}{*}{$5.31 \pm 5.00$} & $5.42 \pm 5.62$ & $5.36 \pm 5.29$ \\
$(\%$ MVIC) & Extension & & $5.32 \pm 5.29$ & $5.23 \pm 4.93$ \\
Middle trapezius & Flexion & \multirow{2}{*}{$11.75 \pm 8.11$} & $12.61 \pm 9.15$ & $12.51 \pm 8.55$ \\
$(\%$ MVIC) & Extension & & $11.18 \pm 7.89^{\text {a }}$ & $10.69 \pm 7.76^{\mathrm{a}}$ \\
\hline
\end{tabular}

Values are expressed as mean $\pm \mathrm{SD}$.

${ }^{\mathrm{a}} \mathrm{p}<0.05$ vs. neutral; ${ }^{\mathrm{b}} \mathrm{p}<0.05$ vs. $30^{\circ}$ flexion 
muscle activities. However, the results of this study could provide fundamental data for understanding neck and scapular muscle activation in head flexed and extended positions in subjects with FHPs, which are commonly performed in daily life.

\section{ACKNOWLEDGEMENT}

This research was supported by Youngsan University Research Grants in 2016.

\section{REFERENCES}

1) Ranasinghe P, Perera YS, Lamabadusuriya DA, et al.: Work related complaints of neck, shoulder and arm among computer office workers: a cross-sectional evaluation of prevalence and risk factors in a developing country. Environ Health, 2011, 10: 70. [Medline] [CrossRef]

2) Fernández-de-las-Peñas C, Alonso-Blanco C, Cuadrado ML, et al.: Forward head posture and neck mobility in chronic tension-type headache: a blinded, controlled study. Cephalalgia, 2006, 26: 314-319. [Medline] [CrossRef]

3) Shaghayegh Fard B, Ahmadi A, Maroufi N, et al.: Evaluation of forward head posture in sitting and standing positions. Eur Spine J, 2016 , 25 : 3577-3582. [Medline] [CrossRef]

4) Nejati P, Lotfian S, Moezy A, et al.: The relationship of forward head posture and rounded shoulders with neck pain in Iranian office workers. Med J Islam Repub Iran, 2014, 28: 26. [Medline]

5) Fernández-de-Las-Peñas C, Cuadrado ML, Pareja JA: Myofascial trigger points, neck mobility, and forward head posture in episodic tension-type headache. Headache, 2007, 47: 662-672. [Medline] [CrossRef]

6) Fernández-de-Las-Peñas C, Cuadrado ML, Pareja JA: Myofascial trigger points, neck mobility and forward head posture in unilateral migraine. Cephalalgia, 2006, 26: 1061-1070. [Medline] [CrossRef]

7) Cheng $\mathrm{CH}$, Chien A, Hsu WL, et al.: Investigation of the differential contributions of superficial and deep muscles on cervical spinal loads with changing head postures. PLoS One, 2016, 11: e0150608. [Medline] [CrossRef]

8) Lee TH, Lee JH, Lee YS, et al.: Changes in the activity of the muscles surrounding the neck according to the angles of movement of the neck in adults in their 20s. J Phys Ther Sci, 2015, 27: 973-975. [Medline] [CrossRef]

9) Lee ST, Moon J, Lee SH, et al.: Changes in activation of serratus anterior, trapezius and latissimus dorsi with slouched posture. Ann Rehabil Med, 2016, 40: 318-325. [Medline] [CrossRef]

10) Lee KJ, Han HY, Cheon SH, et al.: The effect of forward head posture on muscle activity during neck protraction and retraction. J Phys Ther Sci, 2015, 27: 977-979. [Medline] [CrossRef]

11) Gaffney BM, Maluf KS, Curran-Everett D, et al.: Associations between cervical and scapular posture and the spatial distribution of trapezius muscle activity. J Electromyogr Kinesiol, 2014, 24: 542-549. [Medline] [CrossRef] 